\title{
A cone-beam computed tomographic study of C-shaped root and root canal in maxillary molars
}

\author{
Jin-Woo Kim¹, Hyo-Jin Ji', Kyung-Mo Cho'1, Sung-Min Kim², Se-Hee Park* \\ 'Department of Conservative Dentistry, College of Dentistry, Gangneung-Wonju National University, Gangneung, Republic of Korea \\ ${ }^{2}$ Hyundai Senior High School, Seoul, Republic of Korea
}

Purpose: The aim of this retrospective study was to investigate the prevalence rate and types of C-shaped roots and C-shaped canal in maxillary molars by analyzing cone-beam computed tomography (CBCT) in a Korean population. Materials and Methods: Total of 357 CBCT images of maxillary molars (186 first molar, 171 second molar) were evaluated by two Endodontic specialists. Results: Eight types of C-shaped roots and 5 types of C-shaped canals were founded, the prevalence rate of C-shaped roots and canals were 21.0\% and 5.3\% respectively. Conclusion: These anatomical variations were more frequent in second molars than the first molars. Clinicians should have anatomical knowledge about various types of C-shaped root and root canal for successful root canal therapy. (J Dent Rehabil Appl Sci 2015;31(2):104-11)

Key words: cone beam computed tomography (CBCT); maxillary molar; C-shaped root; C-shaped root canal

\section{서론}

근관치료의 성공을 위해서는 정확한 진단, 적절한 치 료계획, 임상경험뿐만 아니라 근관계의 형태와 변이에 대한 지식이 필요하다. ${ }^{1}$ 또한 다양한 형태학적 변이를 가 진 근관을 접하게 되므로 정상적인 형태 외에도 근관의 비정상적인 형태학적 변이에 대한 지식도 매우 중요하 며, ${ }^{2}$ 만약 이런 변이를 발견하지 못한다면 치료실패의 중 요한 요인이 될 수 있을 것이다. ${ }^{3,4}$

여러 가지 해부학적 형태이상 중 C-형 근관은 하악 제2 대구치에서 흔히 발견되는 해부학적 변이로 ${ }^{5,6}$ 치근과 근 관의 횡단면에 대한 이름으로 여러 개의 근관 입구를 가 지는 대신에 근심 설측 선각에서 시작하여 협측을 지나 치수강의 원심측에서 끝나는 180 도 또는 그 이상의 C-형 의 근관 입구를 가진다. ${ }^{7}$

*Correspondence to: Se-Hee Park Associate Professor, Department of Conservative Dentistry, College of Dentistry, Gangneung-Wonju National University, 7, Jukheon-gil, Gangneung, 210-702, Republic of Korea

Tel: +82-2-33-640-2760, Fax: +82-33-640-3103, E-mail: drendo@gwnu.ac.kr Received: May 15, 2015/Last Revision: May 28, 2015/Accepted: June 3, 2015
C-형 근관은 하악 제 2 대구치 외에도 하악 제 1 소구치, ${ }^{8}$ 하악 제1대구치, ${ }^{9}$ 하악 제3대구치, ${ }^{1,10}$ 상악 제1대구치 ${ }^{11,12}$ 및 상악 제 2 대구치 ${ }^{13}$ 에서도 발견되었다는 보고가 있다.

그 동안 하악 대구치의 C-형 근관에 대해서는 이미 많 은 연구와 보고가 있어왔지만, ${ }^{14-16}$ 상악 대구치의 C-형 근 관에 대한 보고는 Newton과 McDonald의 첫 증례보고 이후 드문 편이다. ${ }^{11,12,17,18}$

특히, 발현 빈도에 대한 연구로는 근관치료된 2,175 개 상악 제 1 대구치의 방사선 사진을 조사한 결과 2 개 $(0.091 \%)$ 가 발견되었다는 보고와 ${ }^{19}$ 상악 제 1 대구치에서 $0.3 \%$, 상악 제 2 대구치에서 $4.9 \%$ 에서 발견되었다는 대만 의 연구보고 ${ }^{12}$ 정도로 아주 드물며, 국내에서도 상악 제1 대구치에서 $0.9 \%$, 상악 제 2 대구치에서 $2.8 \%$ 로 발견 되 었다는 학위논문이 단 한편 있을 뿐이다. ${ }^{20}$

상악 대구치에서 C-형 근관의 형태에 관해서는 C-형

Copyright@ 2015 The Korean Academy of Stomatognathic Function and Occlusion. (c) It is identical to Creative Commons Non-Commercial License. 
근관이 근심협측과 구개측 치근의 융합(fusion)으로 생 겼다는 보고와 원심협측과 구개측 치근 또는, 근심협 측과 원심협측 치근이 융합된 증례도 보고된바 있지 만, ${ }^{17,19,21}$ 상악 대구치에서 C-형 치근이나 C-형 근관 형 태의 분류에 대한 연구는 거의 없는 실정이다. ${ }^{20}$

상악 대구치의 근관치료를 시작하기 전에 C-형 근관 의 존재를 미리 알기 어려우며, 주로 근관와동형성 후에 치수강이나 근관입구의 형태가 특이한 경우에 존재를 알게 되는 경우가 대부분인데, 이는 전통적인 방사선 사 진으로는 독특한 해부학적 형태를 판별하기 어렵기 때 문이다. ${ }^{14,22}$

기존의 치근단이나 파노라마 방사선 사진에서는 3 차원적인 구조가 2 차원적인 영상으로 변환됨에 따라 해부학적 구조가 중첩되어서 영상의 왜곡이나 노이즈 (noise)가 생기는 단점이 있지만, 콘빔CT (Cone-beam computed tomography, CBCT)는 치아나 주위 조직의 3 차원적인 영상을 생성하여 이런 문제를 극복할 수 있게 되었다. ${ }^{23}$ 최근에는 근관치료 영역에서도 치료계획을 수 립하기 위해 CBCT의 활용이 늘어남에 따라 근관치료 를 시작하기 전에 C-형 근관을 발견하고 진단하기 용이 해 졌다. ${ }^{24}$

따라서 이번 연구에서는 CBCT를 이용하여 한국인의 상악대구치에서 C-형 치근과 C-형 근관의 발현 빈도와 형태에 따른 분류를 하고자 하였다.

\section{연구 재료 및 방법}

강릉원주대학교 치과병원에 내원한 환자 중 2011년 2 월부터 2014년 10월까지 안면부 외상, 임플란트, 치주 질환, 매복치 등의 이유로 상악 대구치 부위의 D-mode 의 $\mathrm{CBCT}$ 를 촬영한 환자를 대상으로 하였다. 정확한 판 독을 위해 결손부가 있는 치아, 완전히 맹출하지 않거 나 치근이 완성되지 않은 치아 및 제 3 대구치는 실험에 서 제외하였다. 총 234명(남성 126명, 여성 108명)의 CBCT 영상에서 357 개의 상악 대구치를 분석하였다. 그 중 상악 제 1 대구치는 186 개였고, 상악 제 2 대구치는 171 개 였다.

CBCT 장비는 Alphared Vega (Asahi Roentgen Ind, Kyoto, Japan)으로 촬영하였으며, 영상은 전용 이미 지 프로그램인 Xelis Dental Program (Infinitii, Seoul, Korea)을 사용하며 3가지 평면(sagittal, coronal 및 axial) 과 3 차원 영상으로 재구성하여 평가하였다. 각 치아의
Table 1. Representative types of C-shaped roots/canals classified in this study

\begin{tabular}{|c|c|c|}
\hline Type & Symbol & Description \\
\hline 1 & MB-P & Mesiobuccal fused with palatal \\
\hline 2 & DB-P & Distobuccal fused with palatal \\
\hline 3 & MB-DB & Mesiobuccal fused with distobuccal \\
\hline 4 & DB-MB-P & $\begin{array}{l}\text { Distobuccal fused with mesiobuccal } \\
\text { and palatal }\end{array}$ \\
\hline 5 & MB-DB-P & $\begin{array}{l}\text { Mesiobuccal fused with distobuccal } \\
\text { and palatal }\end{array}$ \\
\hline 6 & MB-P-DB & $\begin{array}{l}\text { Mesiobuccal fused with palatal and } \\
\text { distobuccal }\end{array}$ \\
\hline 7 & Y Shape & All roots/canal fused to "Y" shaped \\
\hline 8 & O shape & All fused to "O" shape \\
\hline
\end{tabular}

장축에 따라 횡단면에서 치근의 형태를 치수강에서 근 첨부까지 관찰하여, C-형 치근 및 C-형 근관의 존재를 판정하고, 형태에 따른 분류와 발현 빈도를 조사하였다

C-형 치근은 2개 이상의 치근이 C-형 형태로 융합된 것으로 정의하였고, $\mathrm{C}$-형 근관은 근관의 단면 형태가 C형 형태이거나 C-형 치근을 가진 각 근관의 배열이 C-형 형태인 것으로 정의하였다. 발견된 C-형 치근과 C-근관 은 형태에 따라 8 가지 형태로 분류하였다(Table 1).

\section{결과}

\section{C-형 치근}

이번 연구결과 상악 제 1 대구치와 제 2 대구치에서 C형 치근의 발현빈도와 그 형태에 따른 분류는 Table 2 와 같다.

C-형 치근은 총 357 개의 상악 대구치 전체에서 75 개 (21.0\%)가 발견되었으며, 그 중 상악 제1대구치에서는 186 개의 치아 중 7 개(3.8\%), 상악 제 2 대구치는 171 개의 치아 중 68개(39.8\%)가 관찰되었다. 관찰된 다양한 형태 의 C-형 치근을 8가지 형태로 분류할 수 있었으며, Fig. 1 에서 각 형태에 따른 대표적인 CBCT 영상을 제시하였 다. 각 형태 중 상악 제 1 대구치에서는 근심협측 및 원심 협측 치근이 융합된 형태인 MB-DB형(4개)이 가장 많이 관찰되었고(Fig. 2), 상악 제 2 대구치에서는 근심협측과 구개측 치근이 융합된 형태인 MB-P형(25개)이 가장 많 이 관찰되었다. 
Table 2. Types and numbers of C-shaped roots in maxillary molars

\begin{tabular}{cccccccccccc}
\hline Type & & 1 & 2 & 3 & 4 & 5 & 6 & 7 & 8 & Total \\
\hline \multirow{2}{*}{ First Molar (n=186) } & $\mathrm{n}$ & 1 & 1 & 4 & 0 & 1 & 0 & 0 & 0 & 7 \\
& $\%$ & 0.5 & 0.5 & 2.2 & 0.0 & 0.5 & 0.0 & 0.0 & 0.0 & 3.8 \\
Second molar (n=171) & $\mathrm{n}$ & 25 & 3 & 10 & 14 & 0 & 5 & 10 & 1 & 68 \\
& $\%$ & 14.6 & 1.8 & 5.8 & 8.2 & 0.0 & 2.9 & 5.8 & 0.6 & 39.8 \\
Total (n=357) & $\mathrm{n}$ & 26 & 4 & 14 & 14 & 1 & 5 & 10 & 1 & 75 \\
& $\%$ & 7.3 & 1.1 & 3.9 & 3.9 & 0.3 & 1.4 & 2.8 & 0.3 & 21.0 \\
\hline
\end{tabular}
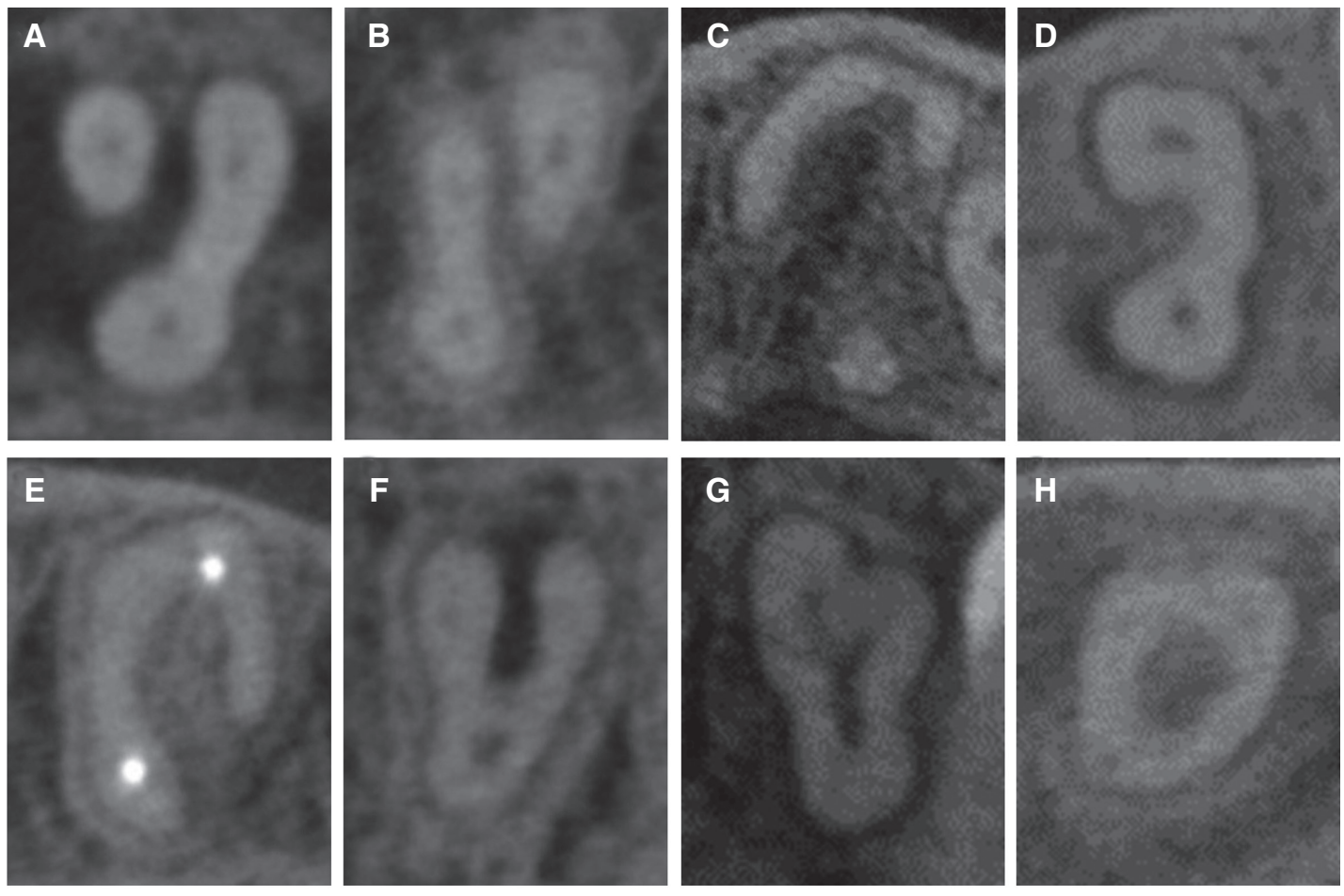

Fig. 1. Representative image of C-shaped root types in this study. (A) Type 1 (MB-P); Mesiobuccal fused with palatal, (B) Type 2 (DB-P); Distobuccal fused with palatal, (C) Type 3 (MB-DB); Mesiobuccal fused with distobuccal, (D) Type 4 (DB-MB-P); Distobuccal fused with mesiobuccal and palatal, (E) Type 5 (MB-DB-P); Mesiobuccal fused with distobuccal and palatal, (F) Type 6 (MB-P-DB); Mesiobuccal fused with palatal and distobuccal, (G) Type 7 (Y Shape); All roots/canal fused to " $Y$ " shaped, $(\mathrm{H})$ Type 8 (O shape); All fused to "O" shape.
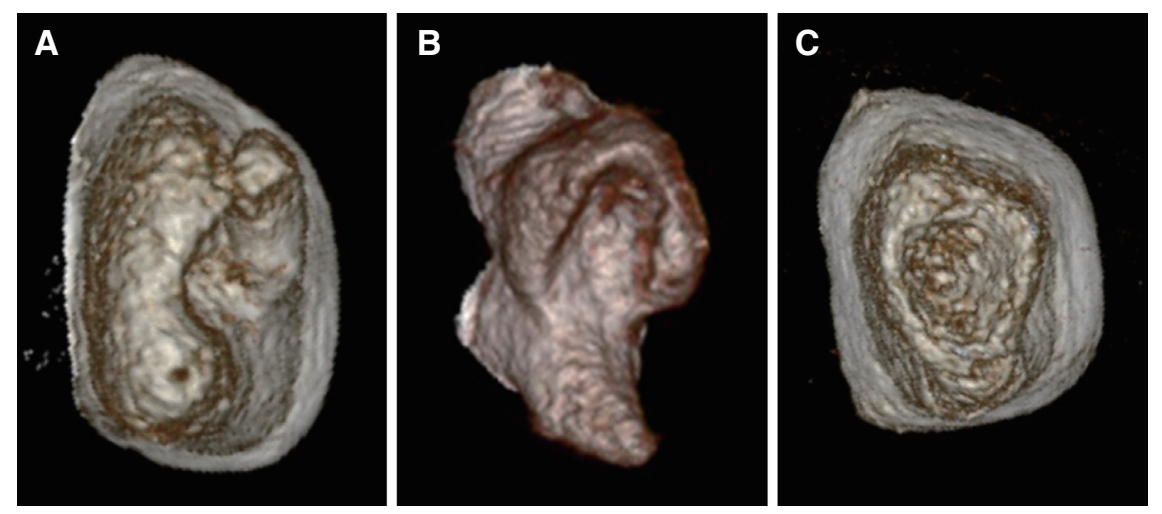

Fig. 2. Representative 3D image of C-shaped root in this study. (A) Type 1 (MB-P); Mesiobuccal fused with palatal, (B) Type 3 (MB-DB); Mesiobuccal fused with distobuccal, (C) Type 8 (O shape); All fused to "O" shape. 


\section{C-형 근관}

상악 제 1 대구치와 제 2 대구치에서 C-형 근관의 발현빈 도와 그 형태에 따른 분류를 Table 3에 정리하였다.

C-형 근관은 총 357 개의 상악 대구치 전체에서 19 개 (5.3\%)에서 발견되었으며, 그 중 상악 제 1 대구치에서 4 개 $(2.2 \%)$, 상악 제 2 대구치에서 15 개 $(8.8 \%)$ 가 관찰되었다.

C-형 근관의 형태는 C-형 치근과 달리 총 5 가지가 관 찰되었으며, Fig. 3에서 각 형태에 따른 대표적인 CBCT 영상을 제시하였다. 각 형태 중 상악 제1대구치에서는 근심협측 및 원심협측 근관이 연결된 형태인 MB-DB 형(3개)이 가장 많이 관찰되었고, 상악 제 2 대구치에서도 $\mathrm{MB}-\mathrm{DB}$ 형(11개)이 가장 많이 발견되었고, 3 개의 근관 이 "Y" 형태로 연결된 Y형(4개)이 그 다음으로 많이 발 견되었다.

\section{고찰}

이 연구는 $\mathrm{CBCT}$ 영상을 활용하여 한국인의 상악 대 구치에서 C-형 치근과 C-형 근관의 발현빈도와 형태에 대한 분류에 대한 후향적 연구이다.
하악 대구치에서의 C-형 근관의 형태의 분류는 비교 적 잘 정리되어 있지만, ${ }^{6,14,25}$ 상악 대구치의 경우 빈도가 아주 낮으며, 형태의 다양성 및 복잡성이 커서 분류가 정립되어 있지 않은 실정이다. 이번 연구에서도 치근은 C-형 형태로 융합되어 있지만 근관의 형태가 C-형이 아 닌 경우도 많이 있어서 C-형 형태의 치근융합과 C-형 근 관을 별도로 분리해서 분석하였다.

이번 연구결과 C-형 형태의 치근 융합의 발현빈도는 상악 제 1 대구치에서 $3.8 \%$ 로 한국인을 대상으로 $\mathrm{CBCT}$ 를 이용한 Cho $(3.3 \%)^{20}$ 의 연구결과와 비슷하였고, 아일 랜드 $(11.0 \%)^{21}$ 나 백인 $(7.7 \%)^{26}$ 의 연구결과에 비해서는 낮은 빈도이지만, 융합된 치근이 하나도 발견되지 않은 태국이나 ${ }^{27}$ 버마의 연구결과 ${ }^{28}$ 와 한국인에서 $0.73 \%$ 로 보 고한 연구결과 ${ }^{29}$ 등을 종합해보면 상악 제1대구치 치근 의 형태에도 인종별 특성이 있는 것으로 생각할 수 있을 것이다.

상악 제 2 대구치에서 C-형 형태의 치근 융합의 발현 빈도는 $39.8 \%$ 로 상악 제1대구치에서보다 상당히 높 았으며, $\mathrm{CBCT}$ 를 이용한 한국인을 대상으로 한 Cho $(20.2 \%)^{20}$ 의 연구와 $\operatorname{Kim}$ 등 $(10.71 \%)^{29}$ 의 연구 결과보다 는 높았지만 아일랜드인 $(43 \%)^{21}$ 이나 백인 $(52.9 \%)^{26}$ 에서

Table 3. Types and numbers of C-shaped canals in maxillary molars

\begin{tabular}{cccccccccccc}
\hline Type & & 1 & 2 & 3 & 4 & 5 & 6 & 7 & 8 & Total \\
\hline \multirow{2}{*}{ First Molar (n=186) } & $\mathrm{n}$ & 1 & 0 & 3 & 0 & 0 & 0 & 0 & 0 & 4 \\
& $\%$ & 0.5 & 0.0 & 1.6 & 0.0 & 0.0 & 0.0 & 0.0 & 0.0 & 2.2 \\
Second molar (n=171) & $\mathrm{n}$ & 1 & 0 & 7 & 0 & 0 & 2 & 4 & 1 & 15 \\
Total (n=357) & $\%$ & 0.6 & 0.0 & 4.1 & 0.0 & 0.0 & 1.2 & 2.3 & 0.6 & 8.8 \\
& $\mathrm{n}$ & 2 & 0 & 10 & 0 & 0 & 2 & 4 & 1 & 19 \\
\hline
\end{tabular}
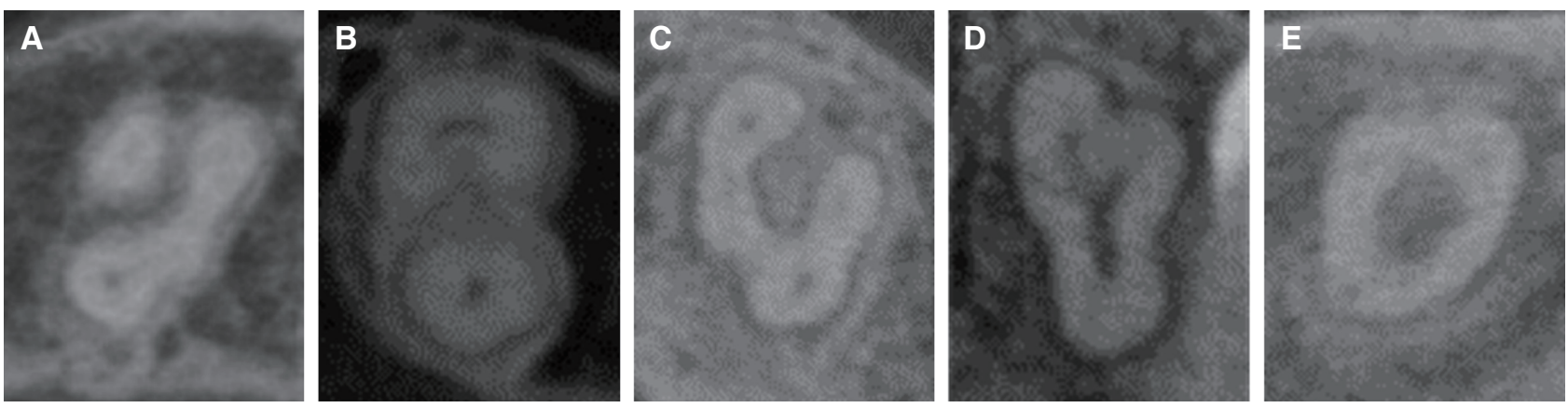

Fig. 3. Representative image of C-shaped canal types in this study. (A) Type 1 (MB-P); Mesiobuccal fused with palatal, (B) Type 3 (MB-DB); Mesiobuccal fused with distobuccal, (C) Type 6 (MB-P-DB); Mesiobuccal fused with palatal and distobuccal, (D) Type 7 (Y Shape); All roots/canal fused to "Y" shaped, (E) Type 8 (O shape); All fused to "O" shape 
의 연구에 비하면 낮은 수치이다. 이는 인종적 특성 외 에도 표본크기, 연구방법 및 판정기준에 따라 결과가 달 라졌으리라 생각되며, 형태학적 연구에서 정확한 비교 를 위해서는 연구방법과 판정기준에 대한 표준화가 필 요할 것이다.

특히 상악 제 2 대구치에서는 모든 치근이 " $\mathrm{O}$ " 형태로 융합되어 있는 형태가 1건 관찰되었는데 이는 Shin 등 $^{3}$ 의 증례보고에서만 1건 보고되었을 뿐인 아주 특이한 형태 이다.

이번 연구에서 C-형 근관의 발현 빈도는 상악 제 1 대구 치에서 $2.2 \%$, 상악 제 2 대구치에서 $8.8 \%$ 로, 상악 제 1 대구 치에서 $0.091 \%$ 인 De Moor 등 ${ }^{19}$ 의 보고와 상악 제 1 대구 치에서 $0.3 \%$ 및 상악 제 2 대구치에서 $4.9 \%$ 인 Yang 등 $^{13}$ 의 보고와 비교하면 두 개의 치아 모두에서 이번 연구에서 발현빈도가 높았다.

C-형 근관의 형태에 관해서는 상악 제 1,2 대구치 모두 MB-DB형이 가장 많았는데, 이는 Yilmaz 등 ${ }^{12}$ 의 증례보 고와 유사한 결과이다. 8가지 형태를 보이는 C-형 치근 과는 달리 C-형 근관의 형태는 제 1 대구치에서는 단지 MB-DB와 MB-P 두 가지 형태만 관찰되었고, 제2대구 치에서는 제 1 대구치에 비해 3 가지 형태가 더 관찰되어 총 5가지의 C-형 근관형태가 발견되었고, de-Moor가 보 고한 형태인 DB-P ${ }^{19}$ 이나 MB-DB-P, B-P는 이번 연구에 서 관찰되지 않았다.

기존의 치과방사선 사진은 2 차원 영상이므로 치아에 존재하는 실제 근관의 수나 형태를 알기 힘들다는 단점 이 있다. ${ }^{30}$ 이를 극복하기 위해서 CBCT를 활용하게 되 었고, $\mathrm{CBCT}$ 영상의 우수성에 관해서는 여러 보고가 있 어왔는데, 치근의 수를 확인하는데 치근단방사선 사진 보다 우수하며, ${ }^{31} \mathrm{CBCT}$ 영상이 실제 조직학적 단면과 의 매우 강한 상관관계가 있다고 알려져 있다. ${ }^{32}$ 또한, $\mathrm{CBCT}$ 영상을 이용한 연구는 치아를 발거하지 않아도 되고, 비파괴적이며, 치아위치, 성별, 나이와 같은 개인 적 정보와 함께 연구할 수 있다는 장점이 있다. ${ }^{33}$

그러나, $\mathrm{CBCT}$ 의 방사선 조사량은 사용하는 장비와 field of view (FOV)의 크기에 따라 매우 다르고, 최소한 으로 조정할 경우 치과용 파노라마사진과 유사하지만, 일반적으로 많은 것으로 알려져 있으며, ${ }^{34}$ 기존의 방사 선 사진에 비해서는 아직 그 해상도가 낮다는 단점이 있 다. ${ }^{33}$

따라서, $\mathrm{CBCT}$ 를 근관의 형태를 평가하는 방법으로 통상적으로 사용하기에는 아직 부적절하며, 근관입구의
형태가 특이하거나 기존의 치근단방사선 사진보다 얻을 수 있는 정보가 많은 경우에 조사량을 줄인 $\mathrm{CBCT}$ 를 사 용하는 것이 좋다고 생각된다.

이번 연구는 한 치과병원에서 촬영된 $\mathrm{CBCT}$ 영상만을 대상으로 하였기 때문에 실험 표본의 크기가 크지 않고 제한적이라는 한계가 있다. 앞으로 다양한 지역, 더 큰 표본의 연구가 필요하며, 형태의 분류에 대한 명확한 기 준을 정립하는 것이 매우 중요하다고 생각된다.

\section{결론}

$\mathrm{CBCT}$ 를 이용하여 상악대구치의 C-형 치근 및 C-형 근관의 발현빈도와 형태에 대해 후향적으로 연구한 결 과 상악 제2대구치에서 상악 제1대구치보다 더 발현 빈 도가 높고, 다양한 형태로 발견되었다. 상악 대구치의 성공적인 근관치료를 위해 다양한 형태의 C-형 치근 및 C-형 근관에 대한 해부학적 지식이 필요하다.

\section{Orcid}

Jin-Woo Kim http://orcid.org/0000-0002-0004-0710

Hyo-Jin Ji http://orcid.org/0000-0002-1968-1390

Kyung-Mo Cho http://orcid.org/0000-0003-3464-9425

Sung-Min Kim http://orcid.org/0000-0002-7607-4319

Se-Hee Park http://orcid.org/0000-0002-4052-4082

\section{References}

1. Sidow SJ, West LA, Liewehr FR, Loushine. RJ. Root canal morphology of human maxillary and mandibular third molars. J Endod 2000;26:675-8.

2. Aggarwal V, Singla M, Logani A, Shah N. Endodontic management of a maxillary first molar with two palatal canals with the aid of spiral computed tomography: a case report. J Endod 2009;35:137-9.

3. Shin Y, Kim Y, Roh BD. Maxillary first molar with an O-shaped root morphology: report of a case. Int J Oral Sci 2013;5:242-4.

4. Slowey RR. Radiographic aids in the detection of extra root canals. Oral Surg Oral Med Oral Pathol 1974;37:762-72.

5. Cooke HG 3rd, Cox FL. C-shaped canal configurations in mandibular molars. J Am Dent Assoc 1979; 
99:836-9.

6. Fan B, Cheung GS, Fan M, Gutmann JL, Bian Z. C-shaped canal system in mandibular second molars: part I-anatomical features. J Endod 2004; 30:899-903.

7. Hargreaves K, Cohen S. Pathways of the pulp. $10^{\text {th }}$ ed. St Louis; Mosby; 2011. p. 217-9.

8. Baisden MK, Kulild JC, Weller RN. Root canal configuration of the mandibular first premolar. J Endod 1992;18:505-8.

9. Rice RT, Gilbert BO Jr. An unusual canal configuration in a mandibular first molar. J Endod 1987;13: $513-5$.

10. Kuzekanani M, Haghani J, Nosrati H. Root and canal morphology of mandibular third molars in an Iranian population. J Dent Res Dent Clin Dent Prospects 2012;6:85-8.

11. Newton CW, McDonald S. A C-shaped canal configuration in a maxillary first molar. J Endod 1984; 10:397-9.

12. Yilmaz Z, Tuncel B, Serper A, Calt S. C-shaped root canal in a maxillary first molar: a case report. Int Endod J 2006;39:162-6.

13. Yang ZP, Yang SF, Lee G. The root and root canal anatomy of maxillary molars in a Chinese population. Endod Dent Traumatol 1988;4:215-8.

14. Fan B, Cheung GS, Fan M, Gutmann JL, Fan W. Cshaped canal system in mandibular second molars: part II-radiographic features. J Endod 2004;30:9048.

15. Kato A, Ziegler A, Higuchi N, Nakata K, Nakamura $\mathrm{H}$, Ohno N. Aetiology, incidence and morphology of the C-shaped root canal system and its impact on clinical endodontics. Int Endod J 2014;47: 1012-33.

16. Jafarzadeh H, Wu YN. The C-shaped root canal configuration: a review. J Endod 2007;33:517-23.

17. Dankner E, Friedman S, Stabholz A. Bilateral C shaped configuration in maxillary first molars. J Endod 1990;16:601-3.

18. Kottoor J, Velmurugan N, Ballal S, Roy A. Fourrooted maxillary first molar having $\mathrm{C}$-shaped palatal root canal morphology evaluated using cone-beam computerized tomography: a case report. Oral Surg Oral Med Oral Pathol Oral Radiol Endod 2011;111:e41-5.

19. De Moor RJ. C-shaped root canal configuration in maxillary first molars. Int Endod J 2002;35:200-8.

20. Cho YH. C-shaped root canal configuration in maxillary molars. Master's thesis. Chosun University, 2013.

21. al Shalabi RM, Omer OE, Glennon J, Jennings M, Claffey NM. Root canal anatomy of maxillary first and second permanent molars. Int Endod J 2000;33:405-14.

22. Lambrianidis T, Lyroudia K, Pandelidou O, Nicolaou A. Evaluation of periapical radiographs in the recognition of C-shaped mandibular second molars. Int Endod J 2001;34:458-62.

23. Venskutonis T, Plotino G, Juodzbalys G, Mickevičiene. The importance of cone-beam computed tomography in the management of endodontic problems: a review of the literature. J Endod 2014;40:1895-901.

24. Solomonov M, Paqué F, Fan B, Eilat Y, Berman LH. The challenge of C-shaped canal systems: a comparative study of the self-adjusting file and ProTaper. J Endod 2012;38:209-14.

25. Melton DC, Krell KV, Fuller MW. Anatomical and histological features of C-shaped canals in mandibular second molars. J Endod 1991;17:384-8.

26. Ross IF, Evanchik PA. Root fusion in molars: incidence and sex linkage. J Periodontol 1981;52:663-7.

27. Alavi AM, Opasanon A, Ng YL, Gulabivala K. Root and canal morphology of Thai maxillary molars. Int Endod J 2002;35:478-85.

28. Ng YL, Aung TH, Alavi A, Gulabivala K. Root and canal morphology of Burmese maxillary molars. Int Endod J 2001;34:620-30.

29. Kim Y, Lee SJ, Woo J. Morphology of maxillary first and second molars analyzed by cone-beam computed tomography in a Korean population: variations in number of roots and canals and the incidence of fusion. J Endod 2012;38:1063-8.

30. Plotino G, Tocci L, Grande NM, Testarelli L, Messineo D, Ciotti M, Glassman G, D'ambrosio F, Gambarini G. Symmetry of root and root canal morphology of maxillary and mandibular molars in a white population: a cone-beam computed tomography study in vivo. J Endod 2013;12:1545-8. 
31. Matherne RP, Angelopoulos C, Kulild JC, Tira D. Use of cone-beam computed tomography to identify root canal systems in vitro. J Endod 2008;34:879.

32. Michetti J, Maret D, Mallet JP, Diemer F. Validation of cone beam computed tomography as a tool to explore root canal anatomy. J Endod 2010;36:118790.
33. Patel S, Dawood A, Whaites E, Pitt Ford T. New dimensions in endodontic imaging: part 1. conventional and alternative radiographic systems. Int Endod J 2009;42:447-62.

34. Palomo JM, Rao PS, Hans MG. Influence of CBCT exposure conditions on radiation dose. Oral Surg Oral Med Oral Pathol Oral Radiol Endod 2008; 105:773-82. 


\section{콘빔CT (Cone beam computed tomography, CBCT)를 이용한 상악 대구치 에서의 C-형 치근 및 근관에 관한 연구}

김진우 ${ }^{1}$, 지효진 ${ }^{1}$, 조경모 ${ }^{1}$, 김성민 ${ }^{2}$, 박세희 ${ }^{1 *}$

${ }^{1}$ 강릉원주대학교 치과대학 치과보존학교실

${ }^{2}$ 서울 현대고등학교

목적: 이 후향적 연구의 목적은 한국인에서 콘빔CT를 이용하여 상악 대구치에서 C-형 치근 및 근관의 발현빈도와 형 태를 분류하기 위함이다.

연구 재료 및 방법: 총 357 개 상악 대구치(제1대구치 186 개, 제 2 대구치 171 개)의 콘빔CT 영상을 두 명의 치과보존과 전 문의가 평가하였다.

결과: 8가지의 C-형 치근 형태와 5가지의 C-형 근관형태로 분류할 수 있었으며, C-형 치근 및 근관의 발현빈도는 각각 $21.0 \%$ 와 $5.3 \%$ 였다.

결론: 이러한 해부학적 변이는 제 1 대구치보다 제 2 대구치에서 많이 발견되었다. 상악 대구치의 성공적인 근관치료를 위해 다양한 형태의 C-형 치근 및 C-형 근관에 대한 해부학적 지식이 필요하다.

(구강회복응용과학지 2015;31 (2): 104-11)

주요어: 콘빔CT; 상악 대구치; C-형 치근; C-형 근관 